\title{
Nasal decongestant and chronic headache: a case of
}

\section{naphazoline overuse headache? [version 1; peer review: 2}

\section{approved, 1 approved with reservations]}

\section{Cherubino Di Lorenzo', Gianluca Coppola², Valeria La Salvia³, Francesco Pierelli4}

${ }^{1}$ Don Carlo Gnocchi Onlus Foundation, Milan, 20100, Italy

2Department of Neurophysiology of Vision and Neurophthalmology, G.B. Bietti Foundation IRCCS, Rome, 00100, Italy

${ }^{3}$ Department of Medical and Surgical Sciences and Biotechnologies and ICOT, "Sapienza" University of Rome Polo Pontino, Latina, 04100, Italy

${ }^{4}$ IRCCS-Neuromed, Pozzilli (IS), 86077, Italy

V1 First published: 11 Nov 2013, 2:237

https://doi.org/10.12688/f1000research.2-237.v1

Latest published: 11 Nov 2013, 2:237

https://doi.org/10.12688/f1000research.2-237.v1

\section{Abstract}

Background: Chronic headache is an incapacitating condition afflicting patients at least for 15 days per month. In the most cases it is developed as a consequence of an excessive use of symptomatic drugs.

Case: Here we report the case of a 34 year-old man suffering from chronic headache possibly related to the overuse of naphazoline nitrate nasal decongestant, used to treat a supposed chronic sinusitis. However, the patient did not suffer from sinusitis, but from a medication overuse headache (ICHD-II 8.3; ICD-10 44.41) that appeared to be due to excessive use of naphazoline.

Conclusion: The use of naphazoline nitrate may result in an analgesic effect upon first use, through activation of adrenergic and opioidergic systems, followed by a pro-migraine effect via a late induction of an inflammatory cascade, modulated by nitric oxide and arachidonic acid. The observation that naphazoline detoxification relieved the patient's headache, indicates that prolonged use of naphazoline may cause chronic headaches. Therefore, physicians should ask for details on the use of nasal decongestants in patients complaining of chronic headache, as they could potentially be suffering from a medicationoveruse headache.

\section{Keywords}

naphazoline, nasal-spray, medication-overuse headache ( $\mathrm{MOH})$, chronic headache, migraine.

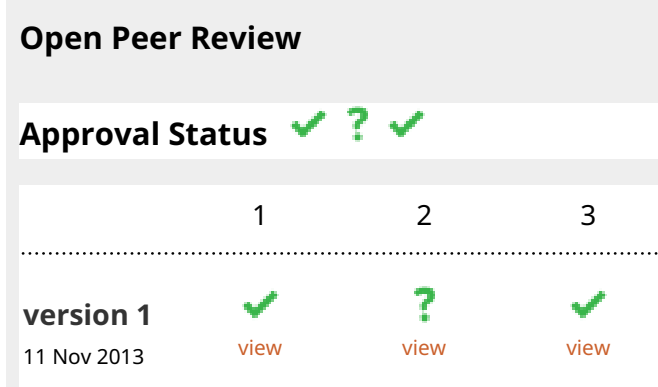

1. Christian Wöber, Medical University of Vienna, Vienna, Austria

2. Dimos Mitsikostas, Athens Naval Hospital, Athens, Greece

3. Mark Obermann ID, University of DuisburgEssen, Duisburg-Essen, Germany

Any reports and responses or comments on the article can be found at the end of the article. 
Corresponding author: Cherubino Di Lorenzo (cherub@inwind.it)

Competing interests: No competing interests were disclosed.

Grant information: The author(s) declared that no grants were involved in supporting this work.

Copyright: $₫ 2013$ Di Lorenzo C et al. This is an open access article distributed under the terms of the Creative Commons Attribution License, which permits unrestricted use, distribution, and reproduction in any medium, provided the original work is properly cited. Data associated with the article are available under the terms of the Creative Commons Zero "No rights reserved" data waiver (CC0 1.0 Public domain dedication).

How to cite this article: Di Lorenzo C, Coppola G, La Salvia V and Pierelli F. Nasal decongestant and chronic headache: a case of naphazoline overuse headache? [version 1; peer review: 2 approved, 1 approved with reservations] F1000Research 2013, 2:237 https://doi.org/10.12688/f1000research.2-237.v1

First published: 11 Nov 2013, 2:237 https://doi.org/10.12688/f1000research.2-237.v1 


\section{Introduction}

Chronic headache ( $\geq 15$ days/month) is an incapacitating condition affecting the $4-5 \%$ of the general population ${ }^{1}$, and can be primary (in which case the headache is not due to other causes but is the disease per se) or secondary (i.e., the symptom of another condition) ${ }^{2}$. In $80 \%$ of cases, the chronic headache is a secondary effect caused by an excessive intake of drugs, mainly analgesics ${ }^{3}$. The excessive intake of pain-killers for more than consecutive 3 months can cause medication overuse headache (MOH), a secondary form of chronic headache, widespread among migraineurs ${ }^{2}$.

Here we report the case of a patient suffering from a chronic headache related to the overuse of naphazoline nitrate, an over the counter nasal decongestant that the patient spontaneously used to treat a self diagnosed chronic sinusitis.

\section{Case report}

A 34 year-old man came to our Outpatient Headache Clinic in Latina ICOT hospital, (Italy) presenting a daily orbito-frontal bilateral headache, that he had been suffering from since he was 18 . The patient had assumed it was a chronic sinusitis.

The patient had not recently undergone any diagnostic evaluation. The only examination that had been performed for his condition was a brain MRI, performed 8 years ago in a private clinic. This MRI detected no abnormalities, except a soft radio-opacity of the paranasal and zygomatic sinuses, and hypertrophy of the nasal mucosa. The general practitioner (GP) did not advice any specific treatment after this MRI-based diagnosis, and patient continued to use naphazoline.

The headache experienced by the patient was bilateral, throbbing, sometimes very severe, and associated with nausea, vomiting, photophobia, osmophobia and worsened by head movements.

The patient had been treated by his GP with medication to relieve the headache (metamizole, rizatriptan, zolmitriptan, acetylsalicylic acid, nimesulide, ibuprofen, naproxen sodium), consumed more than once a day, until the age of 24 . Since then, he had stopped the consumption of such painkillers because he found that naphazoline nitrate nasal spray was more effective. He began with 2 shots $(0,14 \mathrm{mg}$ of drug for any shot) for each nostril 3 times a day, and at the time of presentation, due to pain recurrence, was using the spray 5-6 times a day, and experiencing immediate, yet temporary, relief of the symptoms every time. When asked, the patient said that he had used naphazoline nitrate nasal spray on an occasional basis since the age of 16 , in order to self-medicate for self-diagnosed chronic rhinitis.

During the patient's visit to the clinic, respiratory examination, blood pressure, heart rate, mental status, reflexes, sensory system, cranial nerve, motor system, gait and coordination were normal. Since his headache characteristics were suggestive for a migraine-like headache, further evaluations were required to exclude the diagnosis of an acute sinusitis. Through a CT scan, a relapse of chronic sinusitis was excluded. The patient was then referred to an otolaryngologist, who suggested a detoxification from naphazoline nitrate through the use of aerosol therapy, with mucolytics and steroids, and thermal water spray.
The chronic headache disappeared following the treatment suggested by otolaryngologist. After three months of headache diary recording and clinical re-evaluation, the clinical picture was dramatically changed: patient presented only sporadic attacks of migraine without aura (ICHD-II 1.1). By an anamnesis re-evaluation it emerged that an episodic headache arose in childhood and worsen over the years, until it became chronic by the age of 18 . One year after naphazoline detoxification, the patient has suffered from a few attacks during the year, treated with triptans.

\section{Discussion}

The case we report is suggestive for a chronic headache secondary to naphazoline nitrate overuse, since drug discontinuation interrupted the clinical symptoms. It is not clear however, whether the development of the chronic headache was due to a well-known naphazoline nitrate adverse event (AE) of inducing headache ${ }^{4}$, or whether it was due to a $\mathrm{MOH}$-like occurance, since the patient consumed this drug to treat his headache. Indeed, patient experienced a relief on his headache by naphazoline, this was the reason he supposed, erroneously, to suffer of chronic sinusitis. The anti-migraine effect of naphazoline on our patient raises a question: is it right to regard naphazoline as a migraine medication?

Naphazoline is a sympathomimetic drug, an imidazolinic derivate with marked alpha-adrenergic activity ${ }^{4}$. It enhances the release of noradrenaline from adrenergic termination, immediately relieving the nasal congestion thanks to its vasoconstricting action on the vessels of nasal mucosa ${ }^{5}$. Because of its adrenergic activity, this drug can also produce adverse effects, like rhinitis medicamentosa, hypertension, headache and acute depression of central nervous system with marked sedation ${ }^{4}$. Moreover, cases of ischemic and hemorrhagic stroke secondary to naphazoline have also been reported, mediated by the alpha 1 and alpha 2 adrenergic vasoconstrictive effect that is also exerted on brain vessels ${ }^{6,7}$.

Naphazoline can trigger headaches because of its adrenergic activity (Figure 1). Alpha1 receptors are associated with G-proteins that generate a cascade of events leading to the production of arachidonic acid (AA) and nitric oxide (NO). AA and NO release leads to a late inflammatory vasodilatation ${ }^{8,9}$ that could induce a migraine $\operatorname{attack}^{10}$. Moreover, it is also possible that the same naphazoline nitrate, consumed by our patient, could have contributed to the production and release of further NO by a chemical reduction of the naphazoline salt. In fact, NO donors are currently used to induce migraine attacks in clinical and experimental settings ${ }^{11}$.

However, despite the late effect as a migraine trigger factor, naphazoline might also have an early action as an anti-migraine agent acting on alpha receptors of muscle, immune cells, Locus Coeruleus and spinal cord (Figure 2). In fact, alpha2 adrenergic receptors have a peripheral analgesic effect, thanks to the activation of opioidergic receptors, via endogenous opioid release ${ }^{12}$. Moreover, both alpha1 and alpha2 adrenergic receptors agonists have been proposed to be specifically useful for the treatment of migraine by mechanisms that mediate the early vasoconstrictive effect related to their activation ${ }^{8}$, similarly to triptans that carry out an analgesic action through the serotoninergic agonism that also mediates vasoconstriction. 


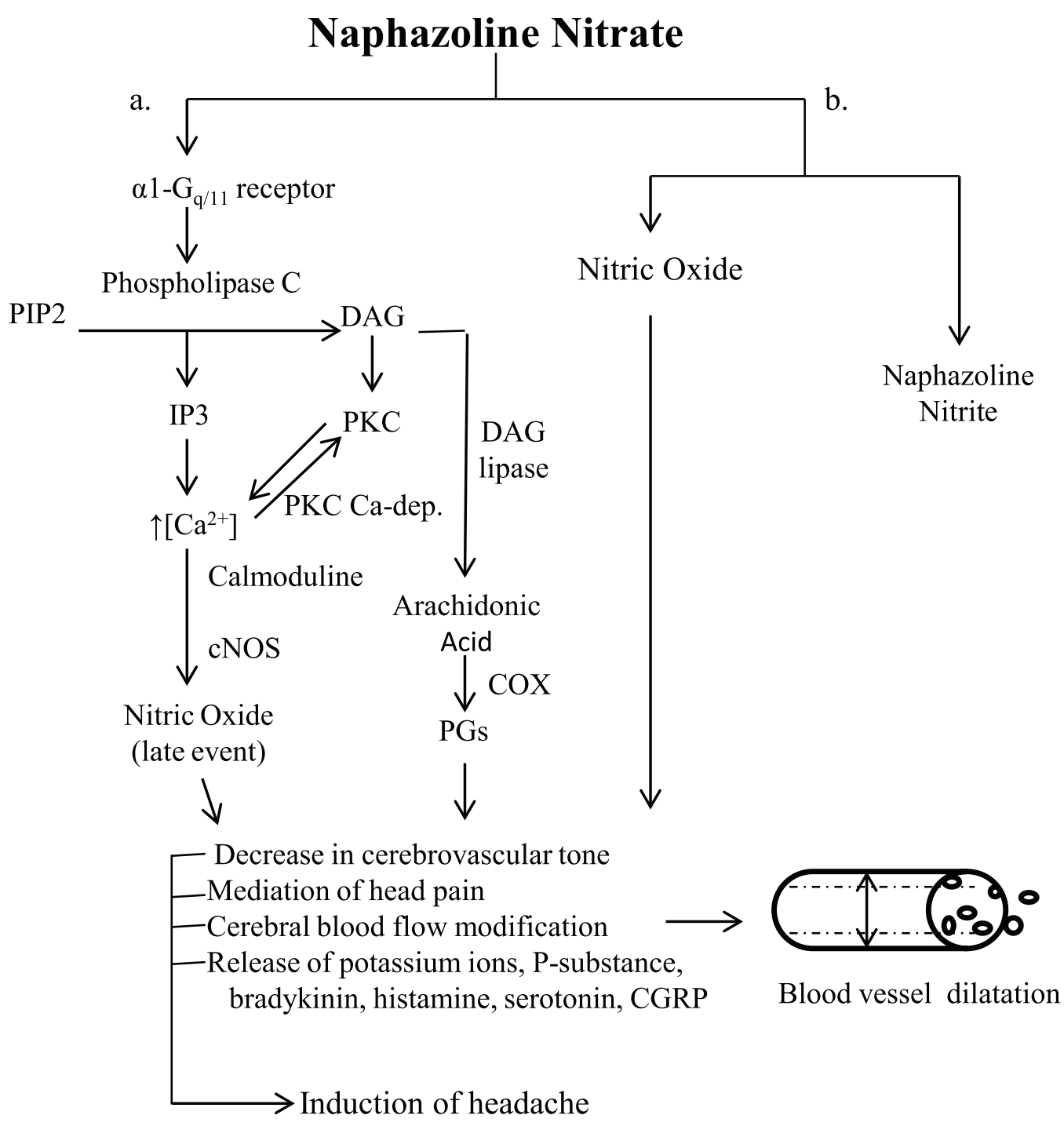

Figure 1. Late events induced by naphazoline that could cause headache. a. Naphazoline activates $\alpha 1$ receptors that are associated with G-proteins that cause the activation of phospholipase C. Phospholipase C cleavesphosphatidyl-inositol 4,5-bisphosphate (PIP2) into two second messengers, inositol 1,4,5-trisphosphate (IP3) and diacylglycerol (DAG) which in turn cause an increase in the level of calcium and protein kinase C. Diacylglycerol, by DAG lipase, takes part in the creation of arachidonic acid which is a precursor in the production of prostaglandins (PGs), mediated by cyclooxygenase (COX). The higher concentration of intracellular calcium allows an increase in the complex of calcium-calmodulin and therefore the activation of constitutive nitrous oxide synthetase (cNOS) with the generation of nitric oxide $^{8,9}$. b. Naphazoline nitrate can contribute to the production and release of further NO by a chemical reduction of the naphazoline salt. Prostaglandins and nitric oxide contribute to the activation of nociceptors and the transmission of the pain pulse from the periphery to the centre $^{10}$. Consequently there is a release of substances such as potassium ions, P-substance, bradykinin, histamine, serotonin and CGRP that keep nociceptors active and result in vasodilatation and extravasation of plasma proteins from the vessels. 


\section{Naphazoline Nitrate}

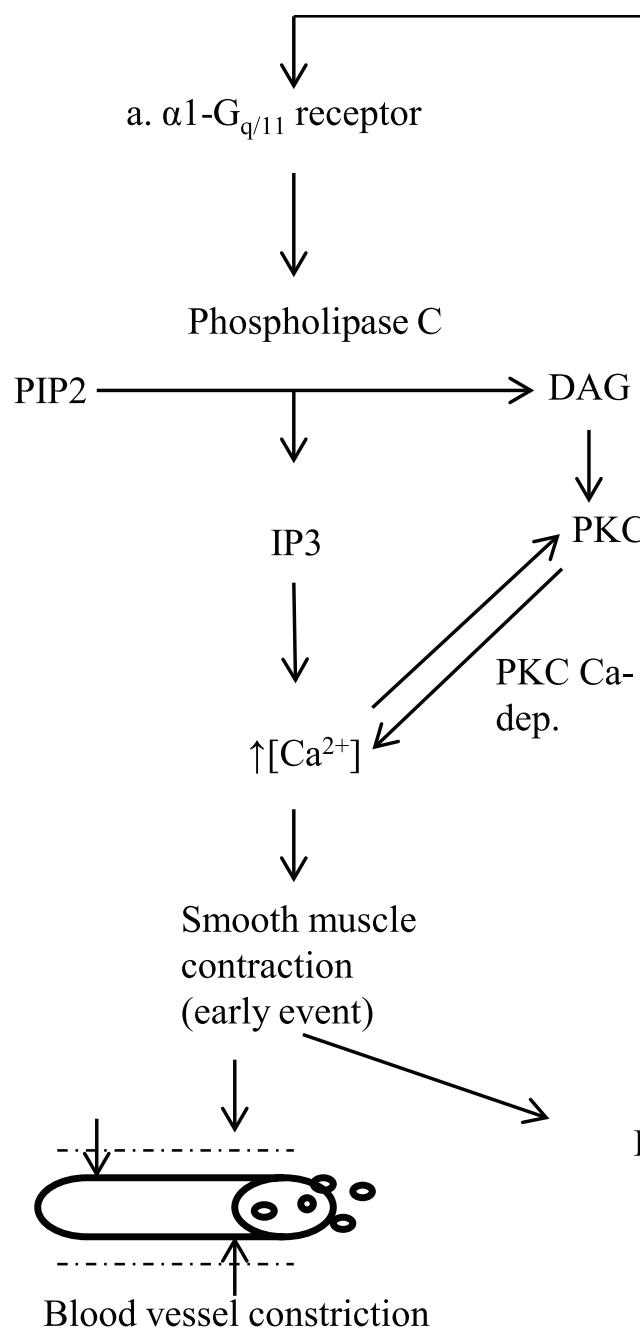

b. $\alpha$-receptor on

immune cells

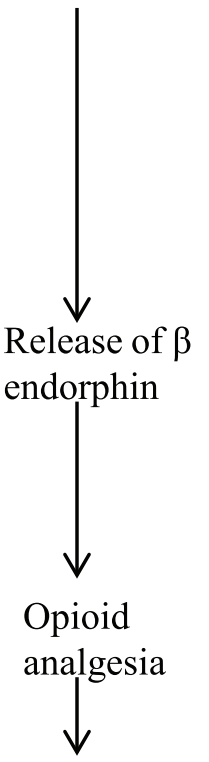

c. $\alpha 2$-adrenoceptors in the LC and spinal cord

Relief from headache

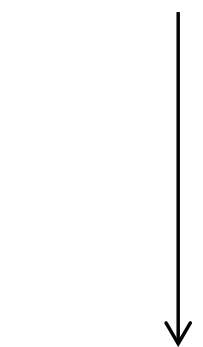

\section{Depression of nociceptive transmission}

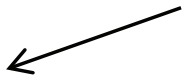

Figure 2. Possible early events that induce peripheral analgesic effect. a. Naphazoline activates alpha1 receptors that are associated with G-proteins that cause the activation of phospholipase C. Phospholipase C cleaves phosphatidyl-inositol 4,5-bisphosphate (PIP2) into inositol 1,4,5-trisphosphate (IP3). Consequently there is a smooth muscle contraction due to an increase of intracellular calcium. b. Alpha-Receptors on immune cells release $\beta$-endorphins that cause opioid analgesia. c. Activation of alpha2 adrenoceptors in the Locus Coeruleus and spinal cord provokes the depression of nociceptive transmission ${ }^{12}$.

Taking together these two opposite effects, it is possible to speculate that naphazoline can have a very early analgesic effect, due to the initial adrenergic activation, and a late migraine-inducing effect, that promotes the recurrence of headache by NO and arachidonic acid modulation.

We could therefore presume that in our patient, in a similar manner to the "triptans effect", naphazoline could exert an antimigraine action but also induce a rebound chronic headache due to medication overuse and/or a proinflammatory cytokine-mediated headache induction. Indeed, our patient had experienced such a sudden analgesic effect; otherwise he would not have continued to take naphazoline.

The observation that naphazoline detoxification leads to the interruption of headache is in line with the guidelines of the International Headache Society that prescribes treatment discontinuation for drugs that can directly induce headache and in cases of $\mathrm{MOH}^{3}$.

In conclusion, although naphazoline may cause headache as an $\mathrm{AE}$, it may also have an early analgesic effect in migraine, as experienced by our patient. Our observation enlarges the spectrum of the 
drugs that can cause $\mathrm{MOH}$ and suggests that physicians should pay attention to the consumption of nasal decongestants in their chronic headache patients.

\section{Consent}

Written informed consent for publication of this case report was obtained from the patient.

\section{Author contributions}

CDL and VLS made substantial contribution to the study and prepared the first draft of the manuscript. GC collected patient's clinical data. FP reviewed the article and approved the final version to be published.

\section{Competing interests}

No competing interests were disclosed.

\section{Grant information}

The author(s) declared that no grants were involved in supporting this work.

\section{Acknowledgements}

The authors would like to thank Giorgia Beolchini who provided assistance in writing the manuscript.
1. Nappi G, Perrotta A, Rossi P et al: Chronic daily headache.

Expert Rev Neurother 2008; 8(3): 361-84.

PubMed Abstract | Publisher Full Text

2. International Classification of Disorders, Committee of the International Headache Society. Classification and diagnosis criteria for headache disorders, cranial neuralgia and facial pain. Cephalalgia. 2004; 24(Suppl 1): 1-150. Reference Source

3. Pascual J, Colás R, Castillo J: Epidemiology of chronic daily headache. Curr Pain Headache Rep. 2001; 5(6): 529-36. PubMed Abstract | Publisher Full Text

4. Rumack BH: POISINDEX(R) Information System Micromedex, Inc., Englewood, CO 2013; CCIS Volume 156, edition expires May 2013. Hall AH \& Rumack BH (Eds): TOMES(R) Information System Micromedex, Inc., Englewood, CO 2013; CCIS Volume 156 edition expires May 2013.

5. Johnson DA, Hricik JG: The pharmacology of alpha-adrenergic decongestants. Pharmacotherapy. 1993; 13(6 Pt 2): 110S-115S- 143S-146S. PubMed Abstract | Publisher Full Text

6. Costantino G, Ceriani $E$, Sandrone G, et al:: Ischemic stroke in a man with naphazoline abuse story. Am J Emerg Med. 2007; 25(8): 983.e1-983.e2. PubMed Abstract | Publisher Full Text
7. Zavala JA, Pereira ER, Zétola VH, et al: Hemorrhagic stroke after naphazoline exposition: case report. Arq Neuropsiquiatr. 2004; 62(3B): 889-89. PubMed Abstract | Publisher Full Text

8. Willems EW, Valdivia LF, Villalón CM, et al: Possible role of alpha-adrenoceptor subtypes in acute migraine therapy. Chephalalgia. 2003; 23(4): 245-257. PubMed Abstract | Publisher Full Text

9. Munaron L: Shuffling the cards in signal transduction: Calcium, arachidonic acid and mechanosensitivity. World J Biol Chem. 2011; 2(4): 59-66. PubMed Abstract | Publisher Full Text | Free Full Text

10. Sarchielli $P$, Alberti A, Codini M, et al.: Nitric oxide metabolites, prostaglandins and trigeminal vasoactive peptides in internal jugular vein blood during spontaneous migraine attacks. Cephalalgia. 2000; 20(10): 907-18. PubMed Abstract | Publisher Full Text

11. Sances G, Tassorelli C, Pucci E, et al:: Reliability of the nitroglycerin provocative test in the diagnosis of neurovascular headaches. Cephalalgia. 2004; 24(2): 110-9. PubMed Abstract | Publisher Full Text

12. Romero TR, de Castro Perez A, de Francischi JN, et al.: Probable involvement of alpha(2C)-adrenoceptor subtype and endogenous opioid peptides in the peripheral antinociceptive effect induced by xylazine. Eur J Pharmacol. 2009; 608(1-3): 23-7.

PubMed Abstract | Publisher Full Tex 


\section{Open Peer Review}

\section{Current Peer Review Status:}

\section{Version 1}

Reviewer Report 23 April 2014

https://doi.org/10.5256/f1000research.2342.r4464

(C) 2014 Obermann M. This is an open access peer review report distributed under the terms of the Creative Commons Attribution License, which permits unrestricted use, distribution, and reproduction in any medium, provided the original work is properly cited.

\section{Mark Obermann \\ Department of Neurology, University of Duisburg-Essen, Duisburg-Essen, Germany}

The authors present an interesting case report of chronic headache possibly related to the nasal decongestant naphazoline. They clearly and reasonably argue that naphazoline may have caused headache as a well known side effect of this drug and/or due to a similar mechanism known from other pain medications (analgesics/triptans/opioids) in terms of medication overuse headache. They laboriously explain the possible pharmacological mechanisms of action that may have caused headache over the long run, as well as early pain relief mechanisms that led to the continued intake of this drug in the first place. All this is highly hypothetical as correctly pointed out by the authors and may or may not stress the possibility of many different drugs that may cause medication overuse headache or may contribute to the development of chronic headache in particular patients.

This case report provides a nice impulse for further research in this direction and emphasizes the possibility of other medications that may cause medication overuse headache beyond triptans, analgesics, etc. This case should make us clinicians more alert for these matters in order to better treat our patients with chronic headache.

Many pre-clinical and clinical studies will be needed before any of the assumptions made by the authors can be confirmed or discarded.

Competing Interests: No competing interests were disclosed.

I confirm that I have read this submission and believe that I have an appropriate level of expertise to confirm that it is of an acceptable scientific standard.

Reviewer Report 17 December 2013

https://doi.org/10.5256/f1000research.2342.r2801 
(C) 2013 Mitsikostas D. This is an open access peer review report distributed under the terms of the Creative Commons Attribution License, which permits unrestricted use, distribution, and reproduction in any medium, provided the original work is properly cited.

\section{Dimos Mitsikostas \\ Neurology Department, Athens Naval Hospital, Athens, Greece}

This is an interesting report showing that naphazoline use was associated with chronic headache in one patient. The patient deserved further evaluation to exclude other brain pathologies related to chronic headache (e.g. no brain MRI or MRA was performed). The authors made a long and nice hypothesis regarding the potential pharmacological induction of headache which, however, needs experimental documentation.

Competing Interests: No competing interests were disclosed.

\section{I confirm that I have read this submission and believe that I have an appropriate level of expertise to confirm that it is of an acceptable scientific standard, however I have significant reservations, as outlined above.}

Author Response ( ) 17 Dec 2013

Cherubino Di Lorenzo, Don Carlo Gnocchi Onlus Foundation, Milan, Italy

We thank Dr Mitsikostas for his kind response.

The decision to not repeat the MRI (the first, performed eight years before, was negative although the clinical picture was already arisen) was a consequence of the very positive outcome experienced by patient after discontinuation of nasal spray. In fact, both the waiting list for CT scan and otolaryngologist consultation were very little, if compared to the MRI list, thus the 'ex adiuvantibus' confirmation of our suspect induced patient to not require another magnetic resonance because he preferred to avoid the discomfort related to the procedure.

We agree that our speculations have to be sustained by further experimental confirmations. However, it is interesting to highlight that the information pamphlet of several nasal decongestants reported headache as a common side effect, but we do not find any notice of it in literature. On the other side, never it was suggested a sudden positive effect for naphazoline on migraine headache. We hope that our report will be the cue for further indepth analysis on the topic.

Competing Interests: No competing interests were disclosed 
(C) 2013 Wöber C. This is an open access peer review report distributed under the terms of the Creative Commons Attribution License, which permits unrestricted use, distribution, and reproduction in any medium, provided the original work is properly cited.

\section{Christian Wöber}

Department of Neurology, Medical University of Vienna, Vienna, Austria

An interesting case report which should be confirmed by further studies.

Competing Interests: No competing interests were disclosed.

I confirm that I have read this submission and believe that I have an appropriate level of expertise to confirm that it is of an acceptable scientific standard.

The benefits of publishing with F1000Research:

- Your article is published within days, with no editorial bias

- You can publish traditional articles, null/negative results, case reports, data notes and more

- The peer review process is transparent and collaborative

- Your article is indexed in PubMed after passing peer review

- Dedicated customer support at every stage

For pre-submission enquiries, contact research@f1000.com 